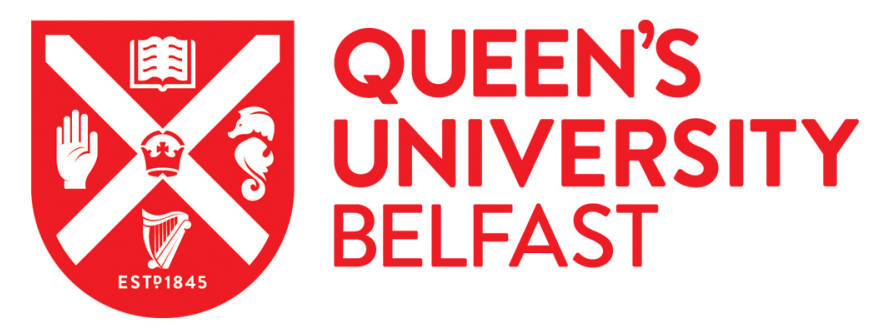

\title{
Heroes on the Hill: A qualitative study of the psychosocial benefits of an intercultural arts programme for youth in Northern Ireland
}

Scrantom , K., \& McLaughlin, K. (2019). Heroes on the Hill: A qualitative study of the psychosocial benefits of an intercultural arts programme for youth in Northern Ireland. Journal of community \& applied social psychology. https://doi.org/10.1002/casp.2401

Published in:

Journal of community \& applied social psychology

Document Version:

Peer reviewed version

Queen's University Belfast - Research Portal:

Link to publication record in Queen's University Belfast Research Portal

Publisher rights

Copyright ( 2018 John Wiley \& Sons, Ltd.

This work is made available online in accordance with the publisher's policies. Please refer to any applicable terms of use of the publisher.

\section{General rights}

Copyright for the publications made accessible via the Queen's University Belfast Research Portal is retained by the author(s) and / or other copyright owners and it is a condition of accessing these publications that users recognise and abide by the legal requirements associated with these rights.

Take down policy

The Research Portal is Queen's institutional repository that provides access to Queen's research output. Every effort has been made to ensure that content in the Research Portal does not infringe any person's rights, or applicable UK laws. If you discover content in the Research Portal that you believe breaches copyright or violates any law, please contact openaccess@qub.ac.uk. 
I probably thought when I was younger that people from other countries aren't that nice... And then when you actually get to know them, it feels like they're no different from anybody else.

-Participant-

\section{INTRODUCTION}

\section{The Northern Irish Context}

In recent years, the conflict in Northern Ireland has dissipated through various diplomatic and social means, and society has entered into a post-conflict period. As a response to postconflict Northern Ireland, initiatives have been implemented such as the European Union's Special Support Programme for Peace and Reconciliation (EUSSPPR), which has contributed over $€ 1$ billion to ameliorating "structural and social/psychological dimensions of the conflict" (Racioppi \& O'Sullivan See, 2007, pg. 362). Currently, the EUSSPPR is in its third wave of funding for 2014-2020 budgeting an estimated $€ 333$ million with two objectives: Reconciling Communities and Contributing to a Shared Society (Community Arts Partnership, 2015). Considering the extensive investments made to promote peace, there is a dire need for robust evidence into what actually works and why.

\section{Bottom-up Peacebuilding}

The phenomenon of peace is often explained in a top-down approach and to follow suite peace initiatives have tended to be implemented in a similar manner. In recent decades, academics and practitioners have shifted toward a decentralized, multi-tiered, bottom-up approach (Lederach, 1997). An often overlooked and underestimated bottom-up approach is the arts in the peacebuilding process. They provide a dynamic platform for peacebuliding considering their intra-personal, inter-personal and communal nature (Lederach, 2005). Bergh \& Sloboda (2010) review various ways that music is used in conflict transformation, such as multicultural events/concerts whose aim is to create awareness around certain conflicts or to build bridges across conflict lines, joint exhibitions or music recordings whereby different groups/communities collaborate toward a common artistic goal, varying approaches to art, music, and drama therapy for victims of trauma and conflict, and the use of music in mediation processes. Shank \& Schirch (2008, pg. 229-230) also list a wide-array of arts-based peacebuilding projects including but not limited to spoken word, hiphop, documentary filmmaking, public murals, installation art, chants, movement therapy, rituals, arts education, and so on.

While the arts hold great peacebuilding potential, according to Racioppi \& O'Sullivan See (2007) the EUSSPPR in Northern Ireland only includes two arts-related projects. In an effort to bring more awareness to the dynamic potential of projects that intersect the arts and peacebuilding, the current study focuses on said intersection and its potential psychosocial 
benefits for participants. The field of arts and peacebuilding is thriving in practice and yet stunted in research. Academic pioneers in this field hail from various disciplines, and while they differ in theory and methodology, they do seem to agree on three points (Bergh, 2007; Bergh, 2008; Bergh \& Sloboda, 2010; Koshland, Wilson, \& Wittaker, 2004; Lance, 2012; Lederach, 2005; Pettan, 2010; Shank \& Schirch, 2008; Zelizer, 2003). First, they agree that the arts and peacebuilding should be tackled with a multidisciplinary perspective. Second, they agree that there is a grave lack of evidence-based initiatives in the field. Third, they reference that the programmes that do exist are often implemented ad hoc without strong theoretical underpinnings. The current study addresses these three points by: adopting a multidisciplinary perspective, expanding the evidence-base from a psychological perspective, and lastly, examining the theoretical underpinnings and potential benefits of one particular programme in Northern Ireland that merges art and peacebuilding.

\section{The Lens: Ecology of Childhood Development}

According to Bronfenbrenner (1993), children develop in multi-layered ecological systems; they are not isolated in time, nor immune to the influence of those around them. Research shows that often these environmental factors have just as much of an influence on development as biological factors and/or genetic traits (NSCDC, 2015; Rutter, 2012). In Bronfenbrenner's (1993) theory, children are surrounded by five concentric systems: the micro-, meso-, exo-, macro-, and chrono-systems. For example, the microsystem includes anyone/thing with direct impact on child's development such as family, peers, and school environment; on the other hand, the chronosystem refers to the child's overarching historical context, such as the influence of exactly when and where in history this child exists. In this study, the individual ecology of each participant is taken into account and is considered a crucial factor in data collection and analysis.

\section{Previous Studies}

Due to the multidisciplinary nature of the current study, previous research is drawn from contact theory, intercultural understanding (ICU), and arts-based peacebuilding (ABP). Contact theory, surprisingly under-represented in the field of $A B P$, is based namely on theories by Allport (1954) and Pettigrew (1998) and posits that when out-groups and ingroups come into contact there is a reduction in prejudice between groups. Allport (1954) suggests that for successful intergroup contact both in- and out-groups must have common goals, the support of authorities, and equal status; they must cooperate toward those goals and must be engaged in casual, ongoing interaction. Two studies with adolescents in Northern Ireland illuminate the benefits of cross-community programs as well as areas for 
improvement. In a quantitative study, Turner et al. (2013) found intergroup contact reduced prejudice and increased positive intergroup relationships for schoolchildren. Additionally, Tomovska's (2010, pg. 133) qualitative study found that children in cross-community programmes desired a more relaxed, positive atmosphere to 'help them get more personal information about each other'.

Tomovska's findings are similar to those of a systematic review of intercultural understanding (ICU) programmes in schools (Walton, Priest, \& Paradies, 2013); both emphasizing the quality of relationships formed by participants. The review included 70 studies from 2000-2012. In their findings, they write that "only building cultural knowledge and cultural awareness can have little if any effect on attitudes or behaviours" (Walton, Priest, \& Paradies, 2013, pg. 185). Instead, for true long-term intercultural understanding to take place, participants need to form prolonged, personal connections in a positive, supportive environment 'in ways that are meaningful and relevant to students' lives' (Walton, Priest, \& Paradies, 2013, pg. 185).

Lastly, there are many studies investigating the effectiveness of ABP yet typically from a non-psychological perspective (Bergh, 2007; Bergh, 2008; Bergh \& Sloboda, 2010; Lederach, 2005; Pettan, 2010; Shank \& Schirch, 2008 Zelizer, 2003). These studies tend to be retrospective in nature, sporadically drawing from themes in contact theory. Vetting the validity of $A B P$ from a psychological perspective would provide the groundwork for creating more evidence-based educational, psychological, and social services and programmes. One consensus in these studies is that long-term effects hinge on the duration and quality of relationships formed during programmes. Interestingly, findings across disciplinary lines are pointing in a similar direction - toward the importance of forming prolonged personal relationships in a relaxed, positive atmosphere. Hence the current study is based on a community programme that does just that.

\section{THE CURRENT STUDY}

\section{Aim and Rationale}

The research question is What are the psychosocial benefits for young people who participate in a cross-community dance programme in the post-conflict society of Northern Ireland?

The general consensus in literature is that participants' perspectives are gravely underrepresented in ABP programs (Bergh \& Sloboda, 2010; Lance, 2012) and contact theory studies (Tomovska, 2010; Connolly, 2000). Previous studies tend to focus on implementers' perspectives or predetermined components of contact theory, respectively. Therefore the aim of the current study is to add young people's voices to discourse on ABP and cross-community programmes. The programme Heroes on the Hill was selected 
because, as recommended by Walton, Priest, \& Paradies (2013), it offered young people an ongoing opportunity to engage with each other in a positive, relaxed way. Heroes on the Hill was a free dance programme for young people 9-16 years old in Dungannon, a small Northern Irish town that is no stranger to the recent Troubles and yet is rich with racial and linguistic diversity. The programme aims were to improve community relations, promote and celebrate the town's diversity, increase social inclusion/integration, and increase participation within the arts (Byrne, 2014).

\section{METHODS}

\section{Design}

Semi-structured interviews were used to gather qualitative data from the participants and facilitators and lasted from 30 minutes to 1.5 hours (Christensen \& Prout, 2002). Ten young people $(n=10)$ were interviewed before the programme and then followed up after the programme, providing comparative data for analysis. Two participants were lost due to attrition; therefore, a total of 18 interviews were conducted with participants. Supplementary data consists of interviews with the dance and music facilitators $(n=2)$ and an observation of the final dance performance. Interviews were held in the Dungannon Youth Resource Centre (DYRC) in a familiar, safe, private room (Connolly, 2003). The researcher participated in a dance rehearsal prior to the first interviews to build rapport and attended a final performance to conclude the participant-researcher relationship in a supportive way (Connolly, 2003).

Interview questions were based on previous studies investigating cross-community and ABP programmes (Bergh, 2007; Connolly, 2000; Tomovska, 2010; Turner et al., 2013; Zelizer, 2003). The first interview focused on participant expectations and perceived aims of the programme, past friendship experiences, and school/family contexts. The second interview focused on overall experience in the programme, skills gained, suggestions for improvement, and new friendships formed. Questions related to contact theory were based on a study in Northern Ireland with a similar age group and explored: experienced diversity, cross-group friendship, perceived peer attitudes, self-disclosure, out-group empathy, and out-group attitudes (Turner et al., 2013).

\section{Participants}

The sample includes ten (10) participants, 11-15 years old, who attended Heroes on the Hill, as well as two programme facilitators. All dancers and drummers were invited to participate. Due to rigid time constraints, a cut-off date for participant consent was implemented. The first ten (10) participants to provide consent were dancers. The few interested drummers did not provide consent in time to participate in the study. The 
researcher scaffolded one participant's interviews due to limited English proficiency. The participants were born in six (6) different nations and had five (5) different home languages. Two were born in Northern Ireland; the rest immigrated to Northern Ireland at ages ranging from 1 to 10 years old from East Timor, Lithuania, Poland, Portugal, and the United States. Such a diverse sample population enhanced the richness of the data.

TABLE 1 Demographics of Participants $(n=10)$ and Facilitators $(n=2)$

\section{Heroes on the Hill: A Description}

Heroes on the Hill was conceptualized and implemented by DU Dance, a professional dance company based in Belfast, Northern Ireland. To the authors' knowledge, only one longitudinal study has been conducted on a previous DU Dance programme; it called for further investigation into the impact of cross-community friendships in future programmes (Muldoon, 2009).

Young people from various backgrounds and schools, who may not have otherwise interacted, were recruited predominantly through Taster Sessions in local schools. They participated as either a drummer or a dancer. The programme lasted six (6) weeks and consisted of biweekly 1.5 hour small-group rehearsals in the DYRC, a sectarian-neutral community space in Dungannon. In other words, there were about 12 total rehearsal days or 18 hours of rehearsal. They were then brought together at the end for three intensive dress-rehearsals before the performance. Rehearsals were led by a Dance Facilitator/Choreographer and a Music Facilitator/Composer, both experienced practitioners and local to Dungannon. DU Dance estimates that 70 young people participated in the final four final performances, which intertwined dance, music, and storytelling, to an audience of approximately 700 people. The performance integrated the young people's cultures by having them raise their national flags and place them together on a symbolic hill; therefore making them all the heroes of their community and hence the name Heroes on the Hill.

The NISRA (2014) reported that in 2011 Dungannon's population was 64\% Catholic and $33 \%$ Protestant/other Christian. The town experienced a recent influx of immigrants between 2004 to 2010, when the largest proportion (20\%) of international migrants to Northern Ireland moved to Dungannon (Russell, 2012). This duality of recent immigration in conjunction with the Troubles offers an extraordinary platform for exploring an ABP from both racial and post-conflict lenses.

\section{Data Analysis}


Thematic analysis was used to investigate latent themes in an inductive approach (Braun \& Clarke, 2006; Lyons \& Coyle, 2007). The epistemological stance is critical realism recognizing that data are influenced by greater social contexts in addition to the psychological realities of the participants themselves (Bhaskar, 1978; Bruner, 1991; Willig, 1999). The researcher read and transcribed interviews and then highlighted meaning units. Themes were generated based on these meaning units and validated by another researcher in multiple sessions. All data were accounted for, including outlying information, in order to enhance the richness of the data.

\section{Ethical Considerations}

Research was approved by the Queen's University Belfast School of Psychology Research Ethics Committee. Consent was granted by all participants and their guardians. Confidentiality and right to withdraw was explained at the beginning of each interview (BandWinterstein et al., 2014; Connolly, 2003). Interviews were audio recorded; electronic files and transcriptions were stored on a password locked computer in a locked room. A debriefing form was provided at the end of the first interview, and a Certificate of Appreciation and a developmentally-appropriate synopsis of findings were provided to participants at the completion of the research (Connolly, 2003).

\section{RESULTS}

Data analysis resulted in four themes. The first theme contextualizes the participants' lives and experiences: Identity, Bullying, and Racism. The other three themes highlight the psychosocial benefits of the programme: Building Self-Confidence, Forming Crosscommunity Friendships, and Developing Intercultural Awareness and Pride. These findings confirm that the programme's aims (Byrne, 2014) to promote and celebrate the town's diversity, increase social inclusion/integration, and increase participation within the arts were indeed met. It is unclear whether the aim of improving community relations was met due to lack of data on this topic. The dance facilitator explained that "there's not so much integration" amongst Dungannon's different cultural dance groups. She reported that often young people get categorized based on their nationality or family culture. Her vision was to pull together their different cultures in a contemporary style, "engage them at the start and make them really interested in dance" before introducing the intercultural aims of the programme. Participant feedback on their general programme experience is not included in this analysis, but is available upon request. 
Throughout the interviews, the young people reported complex notions of identity and were acutely aware of multiple divisions (in- and out-groups) in their community. Many participants shared a sense of dual-identity, belonging to both their home country/culture and Northern Ireland. Bullying and racism were incredibly prevalent and unanticipated themes in their interviews; all of their accounts, as victims and/or witnesses, were based outside of Heroes on the Hill. This made the programme stand out even more as a safe haven for the young people. The only participants who specifically referenced the term "race" or "racism" in their interviews were the four (4) participants of color and the dance instructor, highlighting the fact that their lived experience requires them to be more aware of the concept of race and the community's opinions of their "race". The other six (6) participants used the term bullying to describe their experiences and/or what they witnessed in the community. None of these six participants, all of whom were white, use the term "race" nor "racism" in their interviews. This aligns with sociological research about whiteness. Because whiteness is considered the default standard in society, whiteness and its benefits are often invisible to those that are white (Sue, 2006). Virtually anything appeared to serve as grounds for othering including physical appearance, sexuality, race, socio-economic status, nationality, etc. The following illustrations of victimization are based on race and nationality:

It wasn't really bad words but she was just like offending her. She was calling her an ugly old rat and black thing... She bullies people that are different than her. (P6, Female, 12, Portugal)

These travelers... called this man, I don't know where he was from, but he was coloured, and they called him a black monkey. (P2, Female, 15, East Timor)

People call me foreigner... Go back to your country... like outside [in the town]. [I was] really sad and I didn't wanna say anything back so I just didn't say anything. [It happened] more than once. One year ago...we were playing with this boy. And then his friend came over and was like "Go away. Nobody likes you. Nobody likes foreigners. Go back to your country and all." [He was the] same age as me. He's from here. (P4, Female, 11, Lithuania)

Interestingly, for many participants, sectarianism did not appear to be a concern in Dungannon; a few said 'Belfast [is] the place where it mostly happens.' It is possible that incidences of sectarianism are underreported due to the sensitive nature of the subject or that sectarianism is not perceived as an issue by the young people. The heightened emphasis on the post-conflict status of Northern Ireland could quite possibly undermining the visibility of other issues such as racism, bullying, and prejudice-based behaviors. In other words, through a post-conflict lens, in-groups and out-groups in Northern Ireland are much 
more clearly divided on sectarian lines; yet this overlooks various other forms of tension in the community. The majority of the young people's stories of bullying and victimization were not related to sectarianism. Furthermore, the intersectionality of identity-labels, such as race, class, sexuality, etc., often go overlooked when it comes to identifying discrimination and marginalization in societies (Chakraborti, 2015).

In the face of such adversity, the young people appeared to have begun the process of understanding bullying before their participation in Heroes on the Hill. Many recognized the bully's underlying motivations such as 'jealousy', trying to be 'cool', and trying to get 'attention'. They reported gaining these insights through self-reflection, the influence of family and teachers, and a support group for foreign nationals. In addition to understanding bullying, all of the participants confirmed a conscious desire not to participate in bullying or othering. The following are direct quotes in relation to participants' resilience in the face of bullying.

Sometimes someone bullied me before and my mom would explain it to me. Maybe why they're doing it to make me feel better or something. That they maybe have problems too and they try to make others feel bad and that makes them feel better. (P7, Female, 15, Poland)

I talked to my mom but I went around the subject [bullying]... A couple of weeks later, [she said] 'About that subject, was it you?' And then we talked about it like two hours and she really helped me... I would cry in the toilets in school... [Now] I try to dodge them. I try to keep my head down low and if they would say anything to me, I would stand up and I would definitely tell my mom this time and tell an adult. It is hard what you go through. (P9, Male, 13, Lithuania)

I probably thought when I was younger that people from other countries aren't that nice...And then when you actually get to know them it feels like they're no different from anybody else...It's a small world. We're all the same. She [my best friend] was the first one from a different country I actually knew. So yea, she turned the whole thing around. (P3, Female, 11, N. Ireland)

It's hard, like don't judge a book by its cover... I don't think they [parents] really care. My mommy works with a Protestant and so does my daddy. I think they've realized themselves that there really is no big difference. (P3, Female, 11, N. Ireland)

These experiences reveal that participants have a sense of out-group empathy. This aligns with Piaget's stage theory in childhood development that adolescents of at least about 11 years have entered the formal operational stage of thinking more abstractly and hypothetically (Piaget, 1958). They can step outside of themselves, using metacognition, to view their own actions and the possible feelings of others (Miller, 2009). Participants also 
appear to be highly influenced by their perceived family attitudes, which is typical in the ecology of childhood development, where the family is a microsystem that has a direct impact on children's development (Bronfenbrenner, 1993) and with contact theory, which claims that perceived peer/family attitudes influence cross-community relationships (Allport, 1954; Pettigrew, 1998), and more recently Muldoon, O'Donnell \& Minescu, (2017) who reiterate the importance of family in children's national identity development. Recognizing the participants' complex senses of identity and their stories of bullying helps contextualize their lives; it not only highlights their experiences of adversity but also reinforces their need for a programme like Heroes on the Hill that contributes to the ongoing process of understanding and overcoming such adversity. By promoting diversity, inclusion, and psychological/social development, the programme offers participants a unique way to continue their processes of building resilience.

\section{Building Self-Confidence}

The results reveal the programme's positive impact on young people's mental health by enhancing their self-confidence. Participants were asked the following question in preinterviews, "What do you think the dance facilitator wants you to learn?"; many responded to gain confidence, feel accomplished, express him/herself, have fun, work in a group, learn the dance/new skills, and make new friends. When asked what they learned in postinterviews, participants described that they incrementally gained a sense of confidence during rehearsals and performances. Participant 8 said she was proud that she could 'dance in front of large crowds of people'. Another said:

I was nervous and all so I was just thinking don't fall, don't fall...on the first performance I was so scared and nervous and on the second one I was still a bit nervous but not as much...I started to get a wee bit more confidence since we started doing it for an audience. (P5, Female, 14, Portugal)

In the first interview, Participant 6 said 'I was shy and I didn't really want to dance or do anything,' but by her second interview she said of the experience:

[It] gave me confidence to perform in front of people, so it gave me confidence to speak as well... [like at] the assemblies where we have to do like speaking stuff and I never get picked because I never want to do it. Maybe [now I would consider it]. (P6, Female, 12, Portugal)

This participant recognized that confidence is a transferrable skill that would impact other realms of her life. One participant who had never danced in her life said in her first interview 
'I was all nervous... I don't know if I'm doing this right. I didn't really want to go too wrong', but in her post-interview her nerves had transformed:

I wouldn't say I was too nervous. I was more excited than nervous like yay I'm gonna do something, but I wasn't really nervous just kind of. Since we had done it so many times, I was more confident like we can do this! (P1, Female, 14, USA)

This sense of mastery and increase in confidence, often referred to as self-efficacy, contributes to psychosocial wellbeing and positive mental health. Various studies have confirmed the link between self-efficacy and resilience. For example, if a young person has a sense of self-confidence and mastery, then they are more likely to adapt actively in the face of adversity rather than passively succumb to it (Masten, 2001, 2007; Masten, Best, \& Garmezy, 1991; NSCDC, 2015). In this sense, it is possible that the self-confidence participants gained in their dance abilities could contribute to greater overall self-efficacy and positive well-being. Further research would be required here.

\section{Forming Cross-Community Friendships}

Increasing social inclusion and integration was one of the four main aims of the programme (Byrne, 2014). The dance facilitator further explained this in her interview:

I think young people are ... the best tool to start to break down racism. If they're making friends with people from different cultures, they may go home and chat about them. You kind of start to break down the prejudice... and then with the performance, the wider community can engage in it.

Based on the data this aim was met; almost all participants who completed postinterviews reported forming new cross-community friendships with friends who were different from themselves. This result is especially notable considering the fact that bullying often stems from perceived "otherness" and "differences" between social groups; in Heroes on the Hill there was no reported bullying and instead students of different backgrounds and identities managed to form friendships. Participants showed a great deal of enthusiasm for these new relationships saying 'I've made loads of new friends'; 'Everyone got along so well. And were just open'; the kids at Heroes are 'a lot easier to make friends with'. The only participant to report no new friendships was one male who made contradictory statements saying 'I don't get to meet them' and yet at another point said 'You get to meet new friends, meet new people.' The participant was recently sick and appeared noticeably tired in the second interview; he was also one of only five males in the programme. This calls into question a potential negative consequence of low male involvement in dance:, males who 
are involved have a more limited opportunity to meet other male dancers, which could possibly contribute to the stigma for male dancers.

Although participants expressed a high interest in maintaining these new friendships, their dominant concern was that they attended different schools or lived far away. Social media, Facebook, Instagram, and Snapchat appeared to be their main hope of maintaining these new relationships. Participants also mentioned specific facilitator strategies that helped promote a friendly environment: introductory ice-breaker exercises, partnering up with someone they didn't know, and splitting into small groups to help/teach each other. A few participants felt that the small rehearsal groups made it easier to make friends. For example, one participant shares:

There's this one time in practice ... they said go around and shake hands with people and ask them what their names are and get to know them and all with everybody. And probably if people saw me on my own, they'd come over to me. (P3, Female, 11, N. Ireland)

This participant's words highlight the incredible impact that teacher/facilitator strategies can have on young people's experiences in such programmes. This topic of specific educational/learning pedagogies may be too technical to dive into in the current study. Yet it brings attention to an interesting point for future research: to investigate the specific strategies and scaffolding that teachers and facilitators can implement in peacebuilding programmes that help promote engagement and positive culture amongst participants. In the current study, a majority of participants reported a bicultural identity and also reported a high-level of intergroup contact and new cross-community friendships. Interestingly enough, this aligns closely with a recent editorial by Leman \& Cameron (2017), which explores how young people's identities impact their experiences of intergroup contact. One particular study by Jugert et al. (2017) found that "ethnic minority children were more likely to have friends from other ethnic groups if they identified with a superordinate and shared identity', or in other words if they had a bicultural identity (Leman \& Cameron, 2017, pg. 343). In Heroes on the Hill, even though participants came from different backgrounds and nationalities many of them reported a sense of community with their peers; this could possibly be due to the fact that many of them were foreigners or in some way outsiders in Northern Ireland. This shared identity as outsiders may have been serving as a superordinate, shared identity. In summary, the programme encouraged these crosscommunity friendships and facilitators used specific, effective strategies to foster a safe, positive environment. 
Another programme aim was to promote and celebrate the town's diversity (Byrne, 2014), and in the post-performance interviews, participants' intercultural awareness and pride had flourished astoundingly. They reported that they learned about different cultures, gained pride in their own culture and/or the diversity in Dungannon, and saw the importance of integration in their community. Comments illustrating the perceived power of dance to teach were:

I learned things about different places and all and how people actually live their lives... We were learning stuff about different cultures while dancing at the same time. (P3, Female, 11, N. Ireland)

A number of participants expressed a sense of pride in relation to their performances; Participant 8 said for her it was 'not just an ordinary dance' because it was 'about the history and the heritage of Dungannon'. Participants referenced various ways that the performance promoted diversity and inclusion. Dancers began the performance by displaying various flags that represented the wealth of nationalities represented in Dungannon. Also, participants were invited to record, in their native language, "This is Dungannon. This is our home"; that recording was then integrated into the soundscape of the performance.

Participant 2 shared that in her opinion, the performance's message to the community was:

The fact that there are talented people and the community is just kind of hiding it. It's a good chance to see that there is cultural diversity in this town. You know the flags, the banners? ...It was like "This is Dungannon. This is our home." in different languages. (P2, Female, 15, East Timor)

Participant 6 shared a comprehensive message of the intersection of the performance, diversity, and inclusion:

For us [the performance was] to give us more confidence to be able to speak up and do what we want to do... People do get a lot bullied, because they're not from this country, and we did put a lot of cultural things into the dance. (P6, Female, 12, Portugal)

This participant's words emphasize the fact that the programme allowed participants the opportunity to share their culture with pride and to develop a sense of confidence in a context where their 'differences' are not always accepted or appreciated by the community. Her comment stresses a crucial link between cultural pride, confidence and bullying. This link is encapsulated in one concept: resilience. In essence, resilience is what allows people to overcome and persevere through adversity (such as bullying), and a few of the 
foundational blocks of resilience are cultural pride/identity and self-confidence (NSCDC, 2015). Evidence for this concept will be further explored in the discussion. In the dance facilitator's opinion, young people are 'the people who will change the town' by integrating in and outside of their school environments. When asked, participants shared their opinions of the final message of the programme:

That Dungannon is our home, and we feel comfortable here and all and everyone's welcome... Cause we're all working together. It doesn't matter where you're from or anything... have like a friendlier closer community. Cause if they see that the children are doing it maybe they'll want to do it too, just to like be an example... we got to know each other here. And sometimes adults don't really get to know each other very well. But here we just do it and try to have fun with each other. (P5, Female, 14, Portugal)

That even though you're from a different country you can still meet with each other and basically like, as they put the flags on the stone, you can always make friends with a different nationality person... and connect with other peoples from other countries. (P9, Male, 13, Lithuania)

The overall message not only reached the young people themselves, but in a few cases extended to their families. One participant said that her family commented after the performances:

They thought the stone was cool showing that Dungannon is full of different types of people from all over the place. And that's how the narrator said about new stories coming, bringing their own traditions and everything... they were showing that there's like all different people from everywhere. (P1, Female, 14, USA)

Such comments confirm participants are not only proud of the intercultural nature of the performance, but also conscientious of its potential impact on the community. This increased sense of efficacy and agency within their families and the community is yet another positive outcome contributing to the participants' psychological wellbeing.

\section{DISCUSSION}

In this section, the following highlighted themes and topics are discussed in relation to relevant current literature: the prevalence of bullying in Northern Ireland, the role of resilience, and the role of cross-community friendships. In the conclusion, the programme is evaluated based on its initial four aims to improve community relations, promote and 
celebrate the town's diversity, increase social inclusion/integration, and increase participation within the arts (Byrne, 2014).

First, the high incidents of bullying in participants lives are noteworthy, especially considering the accounts were voluntarily offered by participants. Recent studies mirror these findings such as one based in Northern Ireland which found that almost one-fifth of respondents reported being a victim of bullying behaviour (McGuckin, Cummins, \& Lewis, 2009). A similar study found that school bullying in Northern Ireland may occur at a higher incidence than in the rest of the United Kingdom and Ireland (McGuckin \& Lewis, 2006). Studies in Colombia found that high levels of bullying are associated with factors such as exposure community/family violence, racism, sexism, and the belief that violent behaviour is an effective solution to problems (Chaux \& Velásquez, 2009; Chaux, Molano \& Podlesky, 2009). Considering the fact that bullying is associated with family/community conflict and racism, it should not be overlooked nor underestimated; instead it must be considered a crucial issue and must be addressed by initiatives that aim to reduce sectarianism and racism in Northern Ireland. Interestingly, a recent study found that an arts-based bullying prevention programme was successful in increasing bullying knowledge and decreasing victimization (Haner, Pepler, Cummings, \& Rubin-Vaughan, 2010). Linking bullying specifically to dance, Koshland, Wilson, and Wittaker (2004) found that a movement/dance therapy programme reduced aggressive behaviour in a school setting. Both of these studies imply that art- and dance-based anti-bullying efforts can be effective, yet it cannot be assumed that Heroes on the Hill decreased future victimization.

Next, it is argued that the programme fostered resilience in the young people. Resilience is considered the process through which people overcome and adapt despite experiences of adversity (Rutter, 2012). Many theorists have examined the building blocks of resilience in efforts to identify what actually makes someone resilient. The National Scientific Council on the Developing Child (NSCDC, 2015) presents a set of factors that foster resilience and promote positive outcomes despite adversity. According to the NSCDC (2015), supportive relationships, a sense of mastery, and the affirmation of cultural traditions all contribute to a child's resilience. Heroes on the Hill exposed the young people to all three of these precursors for resilience. They formed a supportive relationship with the facilitators, they gained self-confidence though mastering the skill of dance, and their cultural traditions were affirmed by being integrated into the dance and performance. The current study's findings also align with previous, qualitative studies. Lance (2012) found that participants who joined music/dance peacebuilding programmes in Northern Ireland, Uganda, and the United States experienced a high increase in self-confidence. These findings are similar to Hanebrink \& Smith's (2013) study which used a creative photoessay project with young people to promote peacebuilding and reconciliation in Uganda. Results found that via the 
project the participants explored their identities, formed positive relationships, and gained confidence. Research shows that when children are resilient, they can grow, despite adversity, toward more positive mental and physical health outcomes (NSCDC, 2015). In this sense, Heroes on the Hill offered young people a way to develop their resilience and grow toward more positive, healthy futures.

According to studies in contact theory, cross-community relationships break down prejudices and hence breaks down cycles of direct and structural violence in societies (Tomovska, 2010; Turner, et al. 2013). In the current study, almost all participants integrated and formed new cross-community friendships. Additionally, the programme met Allport's (1954) guidelines for contact theory to be successful: a common goal, support of authorities, equal status, cooperation, and ongoing interaction. The study provides insufficient data as to whether the relationships formed during the programme indeed reduced prejudices and whether these new relationships will be maintained over time. Nonetheless, the participants were allowed to start that process of integration, something often lacking in Northern Ireland where pupils 'rarely have the opportunity to meet and interact in a school setting' (Borooah, \& Knox, 2015, pg. 196). Future research should consider the longevity of the cross-community relationships formed and the role social media plays.

\section{Conclusion}

The programmes aims, to improve community relations, promote and celebrate the town's diversity, increase social inclusion/integration, and increase participation within the arts (Byrne, 2014), are revisited here as a final evaluation of the programme. There is not sufficient data in the interviews to claim that the first aim of improving community relations was met. Participants only rarely mentioned their families' impressions of the programme, and to measure community impact would have required additional, more elaborate methods. On the other hand, three of the programme aims were indeed met. First of all, the programme undoubtedly promoted and celebrated the town's diversity, something that was frequently referenced in participant interviews. Secondly, based on sheer numbers, the programme increased participation in the arts. An estimated 70 young people participated in the final performances, and an estimated 700 community members attended the performances. In other words, almost 800 people participated in the arts due to Heroes on the Hill. Lastly, the aim of increasing social inclusion and integration was met; young people from various ethnicities and nationalities were brought together to work toward a common goal and reported forming friendships with those were were different from themselves. The programme was not only inclusive of young people of diverse backgrounds, but also successfully supported their integration with each other. In a recent report, the UN 
Committee on the Elimination of Racial Discrimination emphasizes 'the intersectionality between racism and sectarianism which must be addressed in a holistic manner in Northern Ireland" (NICEM, 2014, pg. 23). Arts-based programmes like Heroes on the Hill should not be underestimated in their dynamic ability to address such complex issues; in fact they must be considered crucial in promoting integration, diversity and inclusion in Northern Ireland. 


\section{REFERENCES}

Allport, G. W. (1954). The nature of prejudice. Reading Mass.; London: Addison-Wesley. Band-Winterstein, T., Doron, I., \& Naim, S. (2014). 'I take them with me' - reflexivity in sensitive research. Reflective Practice, 15(4), 530-539. doi:10.1080/14623943.2014.900031

Bergh, A. (2007). I'd like to teach the world to sing: Music and conflict transformation. Musicae Scientiae, 11(Special), 141.

Bergh, A. (2008). Everlasting love: The sustainability of top-down vs bottom-up approaches to music and conflict transformation. In S. Kagan, \& V. Kirchberg (Eds.), Sustainability: A new frontier for the arts and cultures (pp. 351). Frankfurt am Main: VAS, Verlag Fur Akademisch.

Bergh, A., \& Sloboda, J. (2010). Music and art in conflict transformation: A review. Music and Arts in Action, 2(2), 2-17.

Bhaskar, R. (1978). A Realist Theory of Science, Brighton, Harvester Press.

Borooah, V. K., \& Knox, C. (2015). Segregation, inequality, and educational performance in Northern Ireland: Problems and solutions. International Journal Of Educational Development, 40196-206. doi:10.1016/j.ijedudev.2014.09.002

Braun, V., \& Clarke, V. (2006). Using thematic analysis in psychology. Qualitative Research in Psychology, 3(2), 77-101.

Bronfenbrenner, U. (1993). Ecological models of human development. Readings on the Development of Children, 2, 37-43.

Bruner, Jerome. (1991) The Narrative Construction of Reality. Critical Inquiry, 18:1, 1-21.

Byrne, M. (2014). DU dance Northern Ireland. Retrieved 09/12, 2014, from http://www.dudanceni.com

Byrne, M. (2014). Project Description - On the Hill. Unpublished manuscript.

Chakraborti, N. (2015). Re-Thinking Hate Crime: Fresh Challenges for Policy and

Practice. Journal Of Interpersonal Violence, 30(10), 1738-1754.

doi:10.1177/0886260514548581

Chaux, E. and Velásquez, A.M. (2009) 'Peace Education in Colombia: The Promise of Citizenship Competencies', in V. Bouvier (ed.) Peace Initiatives in Colombia. Washington, DC: United States Institute of Peace.

Chaux, E., Molano, A. \& Podlesky, P. (2009) 'Socio-Economic, Socio-Political and SocioEmotional Variables Explaining Scho

Christensen, P., \& Prout, A. (2002). Working with ethical symmetry in social research with children. Childhood, 9(4), 477. 
Community Arts Partnership. (2015). EU Programme for Peace and Reconciliation 20142020 - ongoing Retrieved 03/09, 2015, from

http://comartspartner.org/news/funding/european-regional-development-fund-euprogramme-for-peace-and-reconciliation-2014-2020-ongoing/

Connolly, P. (2000). What now for the contact hypothesis? towards a new research agenda. Race, Ethnicity \& Education, 3(2), 169-193. doi:10.1080/13613320050074023

Connolly, P. (2003). Ethical principles for researching vulnerable groups. University of Ulster.

Hanebrink, J. R., \& Smith, A. J. (2013). The Art of Peace in Northern Uganda. African Conflict \& Peacebuilding Review, (2), 195.

Haner, D., Pepler, D., Cummings, J., \& Rubin-Vaughan, A. (2010). The Role of Arts-Based Curricula in Bullying Prevention: Elijah's Kite--A Children's Opera. Canadian Journal Of School Psychology, 25(1), 55-69.

Jugert, P., Rutland, A., Brown, R., Cameron, L., Nigbur, D., Watters, C., ...Le Touze, D. L. (2017). Increasing ethnic diversity moderates longitudinal effects of individual differences on friendship homophily. Journal of Community \& Applied Social Psychology, 27, 411423. https://doi.org/10.1002/casp.2319

Koshland, L., Wilson, J., \& Wittaker, B. (2004). PEACE through Dance/Movement: Evaluating a violence prevention program. American Journal of Dance Therapy, 26(2), 69. doi:10.1007/s10465-004-0786-z

Lance, K. (2012). Breakin' Beats \& Building Peace: Exploring the Effects of Music \& Dance in Peacebuilding (Unpublished masters dissertation). American University, Washington, DC.

Lederach, J. P. (1997). Building peace: Sustainable reconciliation in divided societies. Washington, DC: United States Institute of Peace Press.

Lederach, J. P. (2005). Moral imagination: The art and soul of building peace. New York: Oxford Univ Pr.

Leman, P., \& Cameron, L. (2017). Growing up with diversity: Psychological perspectives. Community \& Applied Social Psychology, 27(5), 339-346. doi: 10.1002/casp.2330 Lyons, E. \& Coyle, A. (2007). Analysing qualitative data in psychology : SAGE Publications Ltd doi: 10.4135/9781446207536

Masten, A. S. (2001). Ordinary magic: Resilience processes in development. American Psychologist, 56, 227-238.

Masten, A. S. (2007). Resilience in developing systems: Progress and promise as the fourth wave rises. Development and Psychopathology, 19, 921-930. 
Masten, A., Best, K., \& Garmezy, N. (1991). Resilience and development: Contributions from the study of children who overcome adversity. Development and Psychopathology, 2(4), 425-444. doi:10.1017/S0954579400005812

McGuckin, C., \& Lewis, C. (2006). Experiences of school bullying in Northern Ireland : Data from the life and times survey (English). Adolescence, 41(162), 313-320.

McGuckin, C., Cummins, P., \& Lewis, C. (2009). Bully/Victim Problems in Northern Ireland's Schools: Data from the 2003 Young Persons' Behavior and Attitude Survey (English). Adolescence, 44(174), 347-358.

Miller, P. (2009) Theories of Developmental Psychology. 5th Edition, Worth Publishers. Muldoon, O. (2009). Psychometric evaluation of the reach.in out programme: End of year 3 report. University of Limerick. Unpublished manuscript.

National Scientific Council on the Developing Child. (NSCDC) (2015). Supportive Relationships and Active Skill-Building Strengthen the Foundations of Resilience: Working Paper 13. http://www.developingchild.harvard.edu

Northern Ireland Council for Ethnic Minorities (NICEM) (2014). Annual Human Rights And Racial Equality Benchmarking Report. Office of the First Minister and Deputy First Minister. Web. 19 Aug. 2015.

Northern Ireland Statistics and Research Agency (NISRA) (September 2014). Northern Ireland census 2011 key statistics summary report. Belfast, UK: National Statistics publication.

Pettan, S. (2010). Applied ethnomusicology: Bridging research and action. Music and Arts in Action, 2(2), 90.

Pettigrew, T. F. (1998). Intergroup contact theory. Annual Review of Psychology, 49(1), 65.

Piaget, J. (1958). The growth of logical thinking from childhood to adolescence, AMC, 10, 12.

Racioppi, L., \& O'Sullivan See, K. (2007). Grassroots Peace-building and Third-party

Intervention: The European Union's Special Support Programme for Peace and Reconciliation in Northern Ireland. Peace \& Change, 32(3), 361. doi:10.1111/j.14680130.2007.00445.x

Russell, R. (2012). Migration in Northern Ireland: An Update. Northern Ireland Assembly. Retrieved 27 August, 2015, from http://www.niassembly.gov.uk/globalassets/ documents/raise/publications/2012/general/3112.pdf

Rutter, M (2012). Resilience as a dynamic concept. Development and Psychopathology. 24. 335-344.

Shank, M., \& Schirch, L. (2008). Strategic arts-based peacebuilding. Peace \& Change, 33(2), 217. doi:10.1111/j.1468-0130.2008.00490.x 
Sue, D. W. (2006). The Invisible Whiteness of Being: Whiteness, White Supremacy, White Privilege, and Racism. In M. G. Constantine \& D. W. Sue (Eds.), Addressing racism:

Facilitating cultural competence in mental health and educational settings (pp. 15-30).

Hoboken, NJ, US: John Wiley \& Sons Inc.

Tomovska, A. (2010). Contact as a tool for peace education? Reconsidering the contact hypothesis from the children's perspectives. Journal of Peace Education, 7(2), 121. doi:10.1080/17400201.2010.498993

Turner, R. N., Tam, T., Hewstone, M., Kenworthy, J., \& Cairns, E. (2013). Contact between catholic and protestant schoolchildren in Northern Ireland : Contact between schoolchildren in Northern Ireland. Journal of Applied Social Psychology, 43(Supplement), E216.

Walton, J., Priest, N., \& Paradies, Y. (2013). Identifying and developing effective approaches to foster intercultural understanding in schools. Intercultural Education, 24(3), 181. doi:10.1080/14675986.2013.793036

Willig, C. (1999) 'Beyond Appearances: A critical realist approach to social constructionist work', in Nightingale, D. and Cromby, J. (eds), Social Constructionist Psychology, Buckingham, Open University Press.

Zelizer, C. (2003). The role of artistic processes in peacebuilding in bosnia-herzegovina. Peace \& Conflict Studies, 10(2), 62. 
